\title{
Data Analytics in Warehouse Management Systems (WMS) Implementations - A Case Study
}

\author{
Natesan Andiyappillai \\ Senior Business Analyst, NFI Industries \\ 1005 Laurel Oak Rd, Voorhees, NJ, 08043, USA
}

\begin{abstract}
Supply Chain management helps businesses to gain competitive advantage in the market and Logistics plays a vital role in the supply chain when it comes to managing and maintaining the inventory accurately and efficiently. The IT Logistics systems help the businesses to run the processes efficiently in the IT applications. Warehouse Management Systems (WMS) is one of the key elements in IT Logistics systems that help keeping the logistics flow seamless while fulfilling the customer orders as expected. Logistics businesses use the WMS application not just to run the warehouse processes in the IT systems but also to optimize the processes by diligently analyzing the various data available in WMS. This article describes and details the various data captured by a WMS and how the Data analytics plays a key role in optimizing the logistics channel by the business by conducting a case study in a leading logistics and supply chain company.
\end{abstract}

\section{Keywords}

Logistics and Supply Chain, Warehouse Management Systems, WMS and Data Analytics.

\section{INTRODUCTION}

Supply chain has become an integral part of an enterprise since last few decades in order to manage the supply chain partners more closely to ensure the smooth material flow across the channel with no or very little interruptions they currently face. When there are more entities and more partners involved in a business, the supply chain becomes complex and so dynamic. Hence, the Supply Chain IT systems come into play to streamline their processes; hence it becomes easy to manage the supply chain efficiently and effectively. A typical supply chain model is shown below to depict the key business partners involved.

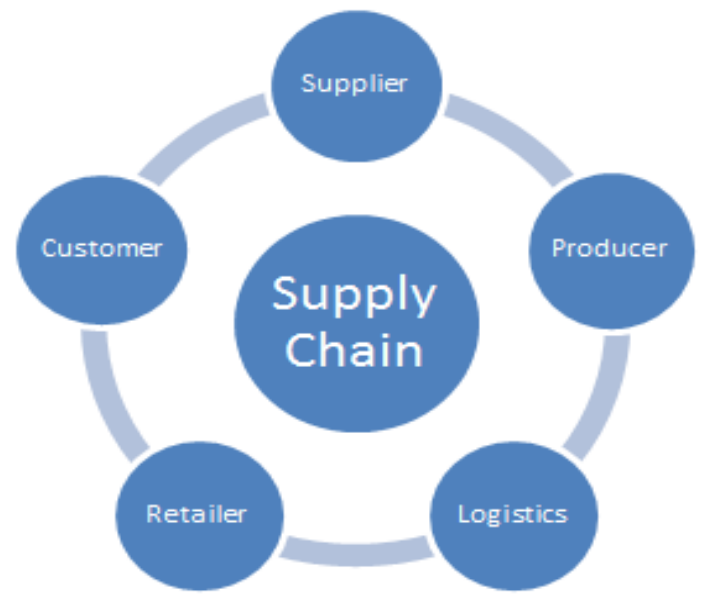

Fig 1. A Typical Supply Chain Model
Being one of the key entities in a supply chain, Logistics has the same kind of challenges in having delivered the right product, right place and at right time. The Logistics IT systems help businesses monitor and control the logistics channel to keep the inventory accurately and optimally. And, the IT Logistics systems also help to communicate with external partners for real time communication. The key logistics processes that are managed by the IT Logistics systems are; Warehousing, Distribution, Transportation and Value Added Services and the below model shows how these functions or systems are integrated under Logistics and its Systems.

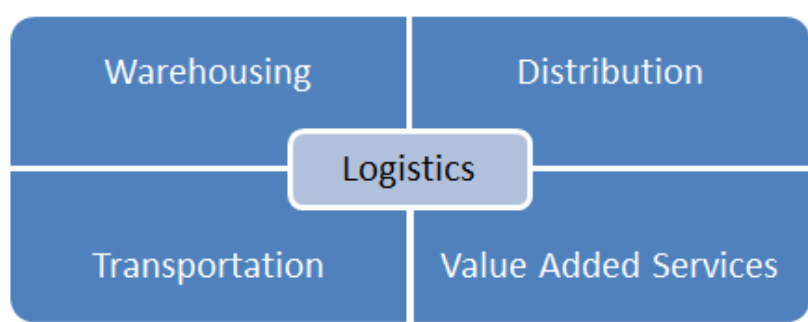

Fig 2. A Model of Logistics Processes or Systems

Warehouse Management Systems (WMS) is helping the businesses to manage all possible Warehouse processes in the IT systems or applications and thus helps to increase the operational efficiency. WMS is also playing a key role in communicating with customer and other external partners for sharing the information electronically for quicker lead time in processing the customer request. The WMS provides the Logistics channel visibility across all the parties involved.

WMS application can store a large number of data based on the architecture of the product. Based on the WMS product capability and functionality, it is generally be classified as Tier-1, Tier- 2 etc. Though there are many types of data that can be made available in WMS, it is critical to analyze the data and apply them to the business for process optimization. There are a number of tools available in the market but how an enterprise use the tools or build the tools to analyze the data for their business matters for the success.

\section{LITERATURE REVIEW}

The supply chain management concept arose from the manufacturing field where the business wanted to manage the material movement in a more controlled way within the facility for the operational efficiency improvement, especially when there are multiple processing units in the facility. This supply chain model eventually helped them to be lean by eliminating the time lag or waste when the material is moved from business unit to another. And, ideally this concept had been adopted by all the other enterprises or businesses as it provides the benefits to the business. 
Logistics is an important element in a supply chain as this ensures the materials flow thru the channel with high visibility and easy to collaborate with the logistics partners. There are many IT logistics systems available in the market and WMS is considered as one of the critical systems in a Logistics company. This is because of the core principle of having the different data captured by the system for operational transparency and easy to communicate and collaborate with all the business partners involved in the business model. The more data captured in WMS and the more data analyzed thru Data analytics opens up the new potential for business growth.

Analytics plays a pivotal role in running a more successful business, and new capabilities exist within today's WMS to deliver a wide range of performance analytics and reporting that highlight how successful or unsuccessful your team is at delivering goods to your customers [1]. It helps to measure the performance of the business and takes necessary corrective actions accordingly. Data analytics offer a new way to look at all that data so visibility results in the right actions at the right time [2]. This is exactly correlates the core principle of the IT Logistics systems which helps to compete in the very tight logistics industry or market.Warehouse management systems continue to improve, and the leading systems today are beginning to provide predictive reporting capabilities as well. Not only do you get actionable real-time analytics, but also reports predicting the future based on your past information [3]. The WMS product vendors been continuously working to upgrade their products based on the market behavior and on the technology advancements to be able to gather more data in WMS for making better business decisions. Today, predictive analytics software are capable of taking digital data across the entire supply chain network, analyzing it, and predicting consumer behavior, the demand for products, as well as the risks and the opportunities in the future [4]. Companies have been investing in the Data storage and Data analytics in the last decade or so due to globalization and ever changing market trend. If a business is able to predict the consumer behavior correctly based on the Data and Data analytics, then it will be the potential market leader on that business at any given time. Based on the literature findings, it is very clear that there are only few research articles been published in the media platforms on the application of Data analytics in Warehouse Management Systems. But, realizing the importance and key role of the Data analytics in WMS, it is attempted here to do a case study in a leading logistics and Supply Chain Company to identify the different data that are captured by WMS and how these data are analyzed and visualized for better and well-informed decisions makings on the operational performance metrics and opportunities for process improvement.

\section{DATA IN WAREHOUSE MANAGEMENT SYSTEMS}

Warehouse Management Systems help to capture the warehouse operational and process data in the system. This is an important task for any logistics service provider to capture the necessary data and use them to mitigate the challenges that they face on; faster product cycle, dynamic market behavior, extreme customer expectations and cost benefits.

The data that are stored in WMS can be from different sources and can be made available as long as the business needs it. The more complexity involved in a business and the more advanced WMS used for the business, the more data can be derived and analyzed for the expected Logistics \& Supply Chain benefits. And, extracting and analyzing these data from WMS becomes inevitable for efficient business forecasting, planning and execution. Performing proper and necessary analysis of these data is crucial for any logistics service provider to be successful in the Logistics and Supply Chain business. This insight data analysis will also help the company to make their supply chain more visible and also to make better informed decisions.

The three different types of data that are captured and stored in WMS are shown in Fig 3 and listed down with the details. The Master Data primarily contains the following;

- Supplier Master

- Item Master

- Customer Master

The Transaction Data primarily includes the following;

$>$ Receiving

$>$ Shipping

$>$ Inventory Tracking

$>$ Cycle Counts

$>$ Inventory Adjustments

$>$ Value Added Services

The Business data helps to understand the mapping and configuration of WMS application based on the customer requirements. With all these three types of data, much more useful business information can be extracted and analyzed thru Data Analytics.

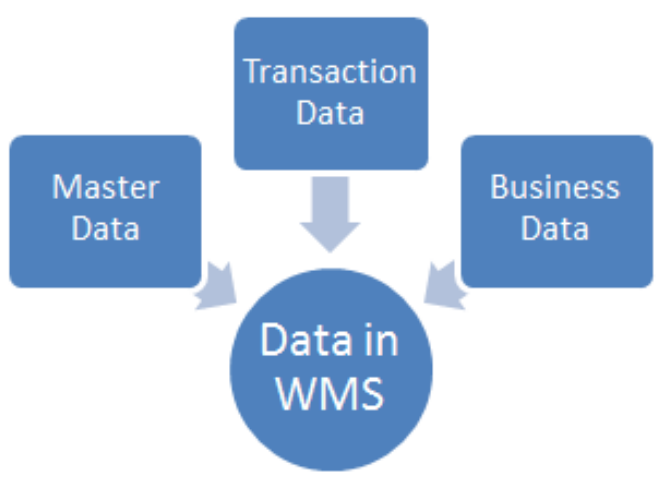

Fig 3. The Data Types stored in WMS

\section{A CASE STUDY ANALYSIS}

This case study has been conducted in a leading logistics and supply chain company. The necessary information for this case study was collected from the project documentations, discussions \& learnings from the expertise, analyzing the WMS application and also the Data Analytics tool. It was observed that this company is operating the business at International level and also using the sophisticated IT Logistics systems to monitor and manage all their processes and partners. This company has been using Tier-1 and Tier-2 WMS applications across the enterprise based on the individual business complexity and cost model.

A decade ago, the company has started to see the growth of the Logistics business at the range of 10 to $15 \%$ a year and started to make remarkable investments in IT WMS solutions and infrastructure. Few years later, the company realized the importance of analyzing the Data that are being captured by WMS solutions, since the same business from different 
facilities provided different results but the customer expectations remains the same. The company then realized the importance of the Data analytics tools to analyze the WMS data for the visibility of each facility. After the decision was made to get a Data Analytics tool, the company had researched all the market leaders in data analytics and reporting tools. It also had evaluated the option of building a custom product within the company, given the fact that the company runs on all major business verticals and IT organization had the expertise to build the product.

The below table shows the different key factors evaluated to determine if the company can opt for a Commerical Off-theShelf (COTS) versus Custom product in developing the tool for Data analytics and reporting. The value indicator point was assigned to each of these key factors (1 - Very Low, 2 Low, 3 - Medium, 4 - Good and 5 - Very Good) by the expertise group setup by the organization and the aggregation of the value indicator points had been one of the critical on the decision making process.

\begin{tabular}{|c|c|c|c|}
\hline S.No & Key Factors & COTS & Custom \\
\hline 1 & $\begin{array}{l}\text { Product Functionality } \\
\text { - How would the } \\
\text { product support the } \\
\text { business in analyzing } \\
\text { the data }\end{array}$ & & \\
\hline 2 & $\begin{array}{l}\text { Product Flexibility - } \\
\text { How flexible the } \\
\text { product would be to } \\
\text { make changes as } \\
\text { needed }\end{array}$ & & \\
\hline 3 & $\begin{array}{l}\text { Deployment Cost - } \\
\text { the Initial cost for } \\
\text { installation, } \\
\text { development and } \\
\text { deployment }\end{array}$ & & \\
\hline 4 & $\begin{array}{l}\text { Maintenance Cost - } \\
\text { the on-going } \\
\text { maintenance cost to } \\
\text { use the application }\end{array}$ & & \\
\hline 5 & $\begin{array}{l}\text { Product Support - the } \\
\text { vendor support on the } \\
\text { product usage }\end{array}$ & & \\
\hline 6 & $\begin{array}{l}\text { Product Scalability - } \\
\text { how scalable the } \\
\text { product is to expand } \\
\text { the roll out across the } \\
\text { enterprise }\end{array}$ & & \\
\hline 7 & $\begin{array}{l}\text { Product Expertise - } \\
\text { the availability of } \\
\text { product expertise at } \\
\text { the enterprise }\end{array}$ & & \\
\hline 8 & $\begin{array}{l}\text { Product supports } \\
\text { different industry } \\
\text { verticals - the ability } \\
\text { of the product to } \\
\text { support different } \\
\text { industry verticals }\end{array}$ & & \\
\hline 9 & $\begin{array}{l}\text { Training Cost }- \text { how } \\
\text { much it would cost the } \\
\text { company to train the }\end{array}$ & & \\
\hline
\end{tabular}

\begin{tabular}{|c|c|l|l|}
\hline & users & & \\
\hline 10 & $\begin{array}{c}\text { Data visualization - } \\
\text { how easy it is } \\
\text { visualize and interpret } \\
\text { the data }\end{array}$ & & \\
\hline & Total & & \\
\hline
\end{tabular}

Fig 4. The Key Factors Value chart

Based on the Key Factors Value chart and the interest of the Leadership team in the organization, the company had decided to develop and build a Supply Chain Reporting Tool (SCRT) internally within the organization.

The company had envisioned that the SCRT to help the business get the right data from the all the data stored in WMS and to identify the opportunities to make changes to the warehouse processes to be better, faster and cheaper. And, it also helps the business to measure the defined metrics per customer requirements and also to meet the service level agreements (SLA) per business contract with the customer.

Understanding the various business or industry processes and preparing the business metrics and requirements matrix accordingly are crucial than actual building up the tool. The company had categorized the data needed for the analysis and reporting and developed a model for Data Analytics as shown below in Fig 5. After the tool was built based on the operational requirements across the enterprise, the tool went thru a numerous rounds of testing and validation before rolled out into Production environment.

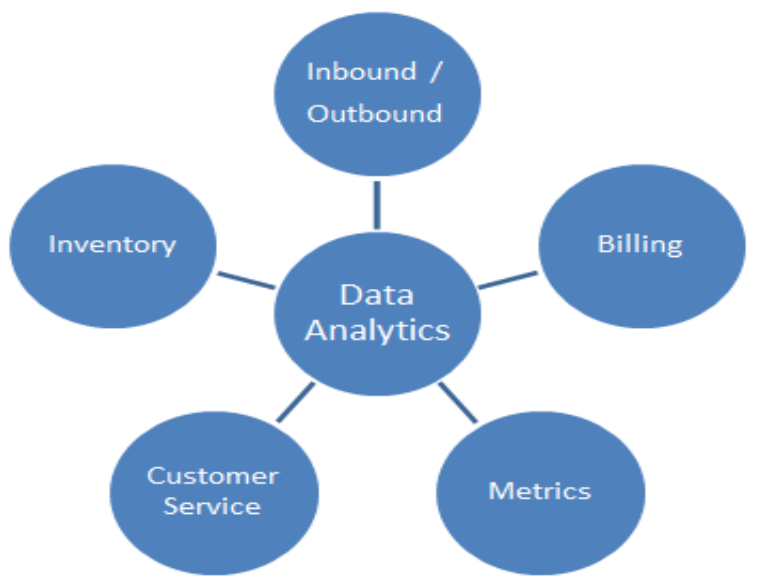

Fig 5. A Data Analytics Model

The businesses have started using the tool SCRT for the below data collection, analysis and reporting in a much more user friendly manner;
* External Customer metrics
* Internal Operational metrics
* Management metrics
* Dashboards

The insights into the different categories of data that are being analyzed in WMS thru the Data Analytics and Reporting tool (SCRT) are discussed below besides how it is benefitting the business;

i) Order and business profile

The data that are being analyzed here are the Inbound / Outbound volume such as \# of orders, order profiles such as 
destination, service levels etc. This helps the business to forecast, plan and align the resources accordingly. It also helps to see the business growth, not just on a specific warehouse or distribution center but in the industry as a whole. New business opportunities are being explored with this data. This also gives the opportunity to measure the customer Returns.

\section{ii) Hardware / Software Configuration}

Data analytics helps the company to take pro-active decisions on the application hardware / software requirements based on the available business data. This includes the software upgrade or new software, sizing the database / application server and security upgrade/ deployments. This also helps to determine the integration of external systems such as EDI and other applications as applicable.

\section{iii) Labor Productivity}

The appropriate Labor are being planned and deployed at any given time based on this Data. It includes the \# of seasonal / specialized workers and the productivity in each warehouse area / function to make the improvements and adjust the Labors accordingly. It also provides the opportunity for business to identify the training requirements for the operators and users based on the labor data profile.

\section{iv) Warehouse Space Optimization}

This data helps to optimize the warehouse space more efficiently as the analytics would help with the location space utilization at any given time and beyond. This also provides the SKU count, profile and categories that are being changed as per the market behavior. And, the business makes the better decisions to optimize the warehouse space accoringly.

\section{v) Devices / Equipments Scalability}

There could many devices / equipments be used at a warehouse based on the business nature, complexity and volume. Some of the common devices to mention are; Access Points, RF devices, MHE equipment, Printers and its Accessories. This data helps to determine the \# of devices / equipments to be used at any given time based on the various business data available, extracted, analyzed and reported. This provides the feasibility to upgrade the IT infrastructure as needed.

\section{vi) Inventory Data}

This data helps to track the inventory end-to-end on the entire supply chain starting the vendor who supplied the product to the facility and the customer who returned the product and see the patterns on the product profile and behavior in the market.

The amount of inventory to be stocked up in a warehouse will be determined and eventually help the vendor to determine the inventory to be manufactured / sourced based on the demand / market profile. This also helps to see the inventory history / accuracy and inventory adjustments that had impacted the financial updates.

vii) Billing Data

The data that are extracted from WMS for calculating the financial expenses incurred in a warehouse / distribution facility are called as Billing data. These billing data are configured in WMS application based on the contract with the customer. The billing data that can be extracted from WMS are primarily categorized into two groups of billing charges;

$$
\begin{aligned}
& >\text { Transactional charges } \\
& >\text { Variable charges } \\
& >\text { Fixed Charges }
\end{aligned}
$$

The Transactional charges are calculated based on the warehouse transactions happen at the facility for a given period of time and these transactions include;

- $\quad$ Receiving and Putaway

- $\quad$ Picking and Packing

- $\quad$ Shipping

- Adjustments

- Cycle counts

- $\quad$ Value Added Services (VAS)

- Miscellaneous

Variable charges include the Labor charges and any over-head charges primarily. And, the fixed charges include the Facility Rent, Management Fees and any other recurring charges.

It has been observed that the company has been extensively using the Data analytics tool, the Supply Chain Reporting Tool (SCRT), for identifying the issues or challenges in meeting the metrics and SLAs and also identifying the opportunities for continuous process improvements. By doing so, the company has confirmed that it has been making changes to the Logistics and WMS processes accordingly for better practices which results in the savings of time and warehouse space at the range of $14 \%$ to $18 \%$ on the warehouse processes.

\section{CONCLUSION}

The researches show that Logistics business becomes complex due to globalization and ever changing market and consumer behavior. And, it is critical for the business not only to use the sophisticated IT WMS systems to capture the right data as much as possible but also to analyze the data extensively and optimize the Logistics channel accordingly to be competitive in the market. By conducting a case study in a leading Logistics and Supply Chain company, it is evident that the business is able to gain competitive advantage by delivering the right product, right place and right time thru the deployment of the Data analytics and reporting tool. This tool helps to company to provide the better customer service by keeping the inventory or stock optimized and helps the company to be a technology leader in the logistics business. Importantly, the company has observed and realized that this Data Analytics tool provides the ROI very clearly to the business as it helps the better informed decision makings, business growth, capacity and capability.

\section{REFERENCES}

[1] Five analytics features to make the most of your WMS data, https://www.explorewms.com/wms-dataanalytics.html, Geoff Whiting, $15^{\text {th }}$ December 2016.

[2] The Path Forward for ERP WMS, https://www.logisticsmgmt.com/article/the_path_forward _for_erp_wms1, Gary Forger, June 7, 2018.

[3] The Importance of Real-Time WMS Reporting \& Analytics, https://www.irms360.com/news/importance_real_time_w ms_reporting_analytics,

[4] Should You Adopt Predictive Analytics in Warehouse Management?, https://articles.cyzerg.com/should-youadopt-predictive-analytics-in-warehouse-management, Hector, $28^{\text {th }}$ Mar 2018. 